Kafkas Üniversitesi Sosyal Bilimler Enstitüsü Dergisi

Kafkas University Journal of the Institute of Social Sciences

Sonbahar Autumn 2020, Sayı Number 26, 441-450

DOI:10.9775/kausbed.2020.024

Gönderim Tarihi: 23.06.2020

Kabul Tarihi: 08.07.2020

OTTO RANK'IN KAHRAMAN KALIBI VE SATUK BUĞRA HAN

\title{
Otto Rank's Hero Pattern and Satuq Bughra Khan
}

\author{
Adem BALKAYA \\ Doç. Dr. Kafkas Üniversitesi \\ Fen Edebiyat Fakültesi \\ Türk Dili ve Edebiyatı Bölümü, \\ adembalkaya81@ hotmail.com \\ ORCID 0000-0002-1309-6406 \\ Çalışmanın Türü: Araştırma
}

$\ddot{\boldsymbol{O}} z$

Destanlar genelde konuların tarihten alılar ancak bu metinler birer tarih metni olarak görülemez. Hatta kimi destan kahramanlarının dönemi veya idare ettikleri devletle ilgili tarih kayıtları olmasına rağmen yaşayı yaşamadıkları veya tam olarak hangi tarihi kişiliği karşıladıkları tartışılmaktadır. Bu nedenle destan kahramanları ayrı ayrı çalışılmalıdır. Anlatı kahramanı hemen hepimizin kendisinde bireysel yaşanmışlıklarımızdan izler bulmaya çalıştığımız veya yaşanamamışlıklarımızı yaşanabilir kılacak niteliklerle donattığımız bir nevi kendimizi temsil misyonu ile anlatı odă̆ yaptı̆̆ımız varlıktır. Destan kahramanı kendi adına değil temsil ettiği toplum adına hareket eder. Böylece aslında destan kahramanı için söylenecekler aynı zamanda kahramanın ait olduğu toplumu da bağlar. Karahanlı Hükümdarı Bezir Arslan Han'ın oğlu olarak dünyaya gelen ve Karahanlı Devleti'ne hükümdarlı eden Satuk Buğra Han ilk Müslüman Türk hükümdarı olarak kabul edilir. Tarihi bilgiler dışında Satuk Buğra Han'ın hayatı destanlaştırılarak anlatılmıştır. Tezkire-i Buğra Han, Buğra Hanlar Tezkiresi, veya Tezkire- $i$ Üveysiye isimleriyle birden çok yazma nüshası olduğu bilinen destandan ilk bahseden kişi Shaw Barkley olmuş onu M. F. Grenard takip etmiştir. Türkiye'de çeviri olarak Ülkü dergisinde ilk yayımlayan da Osman Turan olmuştur. Karşımıza tarihi bir kişilik dışında bir destan kahramanı olarak çıkan Satuk Buğra Otto Rank'ın kahraman kalıbı açısından değerlendirilecektir. Bu kalıpta yer alan maddelerden kaçı ile örtüştüğü gösterilecektir.

Anahtar Kelimeler: Kahraman, Satuk Buğra Han, Karahanlılar, Otto Rank

Abstract

Epics usually take their subjects from history, but these texts cannot be considered as a text of history. Even though there are some historical records about the period of some epic heroes or about the state they ruled, it is even discussed whether they lived or not or which historical personality they are corresponding to. For this reason, epic heroes should be studied separately. The hero of narration is the one with whom we try to find traces of our individual experiences in all of us, or a kind of being that we have equipped with the qualities making what we have not experienced as livable and we have made a narrative focus with the representation mission of ourselves. The epic hero acts in the name of the society, which he represents, not in his name. Thus, the things to be said for the epic hero also concern with the society of the hero. Satuq Bughra Khan who was born as the son of Bezir Arslan Khan, the ruler of the Karakhanid and ruled Karakhanid State is accepted as the first Muslim Turkish ruler. Besides the historical information, the life of Satuq Bughra Khan has been narrated with epic. Shaw Barkley was the first person to talk about the epic 
known as having more than one manuscript copy with the names of Tezkire-i Bughra Khan, Buğra Hanlar Tezkiresi or Tezkire- $i$ Uveyyiye, and he was followed by M. F. Grenard. Osman Turan became the first person publishing it as a translation in Ülkü magazine in Turkey. Satuq Bughra who appeared as a legendary hero rather than a historical personality will be evaluated in terms of Otto Rank's hero pattern. It will be shown that how many of the items in this pattern he overlaps with.

Keywords: Hero, Satuq Bughra Khan, Karakhanids, Otto Rank

\section{GİRIŞ}

İnsanın en büyük gayesi aynı zamanda en büyük ihtiyacı olan merak duygusunu tatmin etmek ve hayatı anlamlandırırken her şeye mantıklı çözümler ve açıklamalar bulmaktır. Modern insan da ilkel insan da dünyayı kendince bir şekilde anlamlandırmıştır ancak bu anlamlandırmayı gerçekleştirirken kullanılan argümanlar farklı olmuştur. İlkel için etrafinda olan biten her şeye mantıklı açıklamalar bulan anlatılar mit olarak tanımlanır. Ancak zamanla ortaya çıkan rasyonel bilgiler miti sorgulanır hale getirmiş ve yeni açıklamalar doğurmuştur. Mit döneminin hemen ardından destan dönemi başlamış ve havada olan birçok şeyin destanla ayağı yer tutmuştur. Ancak unutulmamalıdır ki destanlar ortaya çıkışları itibariyle yine mitlerin kanatları altında onların verileri üzerine tesis edilmişlerdir. Özkul Çobanoğlu epik destanları mitlerin gölgesini ve çizgilerini taşımakla birlikte "gerek kahramanlarının ve gerekse olayların akışılla birlikte tarihe ait zamanlarda olmuş olayların hikayesi inancıyla, sözlü kültür ortamında ve yüz yüze bir iletişim bağlamında teatral çizgilere sahip bir biçimde anlatılıp nakledilen, en geniş anlamıyla kahramanlık ana temalı öyküler (Çobanoğlu, 2011. s.16)" diye tanımlar.

Destan metinleri merkeze kahramanı alarak bütün olay örgüsünü onun üzerine kurar. "Epik destan anlatım geleneğinin en büyük kuralı dikkati başkahraman üzerine toplamadır (Çobanoğlu, 2011. s. 18)." Ancak kahraman burada bireysellikten uzaktır ve bütün kolektif adına hareket eder. Metin hangi topluma aitse kahraman o toplum yararına hizmet eder hatta kahramanlığa geçişte bütün toplumu ilgilendiren bir sorunu halletmelidir. "Destanlarda karşımıza çıkan merkezî kahraman tipi.... millî birlik anlamına gelen törenin koruyucularıdır. Destan kahramanları halkın onlara en ihtiyaç duyduğu dönemlerde ortaya çıkar... Bu zamanlarda millî birliğin yeniden kurulmasının en ideal yolu halkı etrafina toplayabilecek kadar güçlü ve donanımlı bir liderin varlığıdır. Destan kahramanlarının her bakımdan olağanüstü özelliklerle tasvir edilmeleri, halkın bu kahramanlar etrafında birleşmesini izah etmenin en edebî yoludur (Düzgün, 2007. s.126).”

Anlatıların merkezi olan kahramanlar kimi araştırmacılar tarafından ortak özelliklerin tespiti amacıyla geliştirilen kalıplara göre okunmaya 
çalışılmıştır. Bu kalıplardan biri J. G. Von Hahn'ın ileri sürdüğü ve “Aryan Sürgün ve Dönüş Formülü" veya "Aryan Kahramanı Biyografik Modeli" olarak bilinen kalıptır. Hahn bu kalıpta dört ayrı bölüm halinde şu maddeleri verir:

\section{Doğum:}

- Kahraman gayrı meşru olarak doğar.

- Annesi ülkenin prensesidir.

- Babası bir tanrı veya bir yabancidir.

\section{Gençlik:}

- Kahramanın yükselişinin işaretleri vardır.

- Bu nedenle terk edilmiştir.

- O, hayvanlar tarafindan emzirilir.

- Çocuksuz bir çoban çifti tarafından büyütülür.

- O, yüksek ruhlu bir gençtir.

Dönüş:

- O, yabancı bir ülkede hizmet edeceği bir iş arar.

- O, geriye muzaffer olarak döner ve tekrar yabancı ülkeye gider.

- O, gerçek düşmanlarını kılıçtan geçirir ve ülkeyi yönetmeğe başlar ve annesini kurtarır.

- O, şehirler kurar.

- Onun ölüm şekli olağanüstüdür.

İkinci dereceden Şahıslar:

- O, insest ilişki nedeniyle lanetlenmiştir ve genç ölür.

- O, hakarete uğrayan bir hizmetçisinin eliyle intikam için öldürülür.

- O, daha genç olan kardeşini öldürür (Çobanoğlu, 2012:208).

Başka bir kahraman kalıbı da Otto Rank tarafından yapılmıştır.

Rank'ın kalıbı da şu şekildedir:

- Kahraman, sıra dışı bir ailenin çocuğudur.

- Kahramanın, babası bir kraldır.

- Kahramanın ana rahmine düşüşş şartları zordur.

- Kahramanın doğumuna karşı kehanetler ve uyarılar vardır.

- Kahraman, suya bir kutu içinde bırakılır.

- Kahraman, hayvanlar veya iyi insanlar tarafindan korunur.

- Kahramanı, dişi bir hayvan veya mütevazı bir kadın emzirir.

- Kahraman büyür.

- Ve gerçek ailesini bulur.

- Babasından intikamını alır.

- Kahraman, halk tarafından tanınır ve kabul edilir. 
- Kahraman rütbe kazanır, yükselir ve onurlanır (Çobanoğlu, 2012: 209).

Lord Raglan da Geleneksel Kahraman Kalıbı başlığı ile yirmi iki özellik sayar. Bu özellikler birçok araştırmacı tarafından kimi kahramanlar üzerinde denenmiştir (Aktaş, 2014., Bars, 2014: Köse, 1999a; 1999b; 2000; Oğuz, 1998; 1999). Bunlar;

1. Kahramanın annesi soylu bir bakiredir.

2. Babası bir kraldır.

3. Baba çoğunlukla kahramanın annesinin yakın bir akrabasıdır.

4. Kahramanın anne karnına düşüş şartları olağan dışıdır.

5. Kahraman aynı zamanda bir tanrının oğlu olarak kabul edilir.

6. Çoğunlukla baba tarafından onu öldürme girişiminde bulunulur.

7. Kahraman gizli bir yere gönderilir.

8. Uzak bir ülkede evlat edinen bir aile tarafindan büyütülür.

9. Kahramanın çocukluğu hakkında bize bir şey anlatılmaz.

10. Kahraman yetişkinlik çağındayken gelecekte kral olacağı yere gider.

11. Kahraman kral, dev, ejderha veya vahşi bir hayvana karşı kazandığ 1 zaferden sonra

12. Çoğunlukla kendisinin selefinin kızı olan bir prensesle evlenir.

13. Kral olur.

14. Bir süre herhangi bir hadise olmaksızın ülkeyi yönetir.

15. Kanunlar yazar. kaybeder.

16. Daha sonra kahraman tanrıların ve/veya halkının sevgisini

17. Tahttan ve şehirden uzaklaştırılır.

18. Kahraman esrarengiz bir şekilde ölümle tanışır.

19. Çoğunlukla bir tepenin üzerinde ölür.

20. Çocuklarından hiçbiri, eğer varsa, onun yerine tahta geçemez.

21. Kahramanın vücudu gömülmez.

22. Kahramanın gömülü olduğu kabul edilen bir veya birden fazla kutsal mezarı vardır (Raglan, 1998. s. 126-138).

Bu çalışmada Otto Rank'ın kalıbı esas alınacak ve on iki madde Satuk Buğra Han Destanına uygulanacaktır.

\section{SATUK BUĞRA HAN DESTANI}

Satuk Buğra Han, IX. yüzyılın sonlarında doğar, babası Karahanlı Hükümdarı Bezir Arslan Han'dır. Bezir Arslan Han'ın ölümü üzerine Balasagun'da Karahanlı tahtına II. Arslan Han çıkar. Satuk Buğra Han 
annesiyle birlikte Kâşgar'a gidip amcası Kadır Han Oğulçak'a sığınır. Amcası adına vergi tahsil etmek üzere Kâşgar yakınlarındaki Artuç'a giden Satuk, burada Tezkire-i Satuk Buğra Han'da kuvvetli bir âlim ve Üveysî bir kutub olarak tanıtılan Ebû Nasr b. Mansûr ile tanışır. İslamiyeti kabul eder ve Abdülkerim ismini alır (Hunkan, 2009. s. 181-182). Satuk Buğra Han'ın İslam dinini kabul ederek Türkleri büyük ölçüde İslamlaştırması halk muhayyilesinde oldukça önemli bir yer tuttuğu için hayatı etrafında mucizelerle dolu anlatılar ortaya çıkmıştır.

Satuk Buğra Han Destanı ile ilgili İngiliz Robert Shaw Barkley 1878 y1lında, A Sketch of the Turki Language as Spoken in Eastern Turkistan adlı eserinde ilk defa Satuk Buğra Han'dan bahsetmiş ve Arap harfli matbu bir nüshasını yayımlamıştır. Daha sonra Fransız M. F. Grenard 1889 tarihli bir el yazması nüshasını Journal Asiatique dergisinde 1900 yılında neşretmiş ve çalışmasında Sahw'ın metnini de esas alarak kapsamlı bir değerlendirme yapmıştır. Türkiye'de destanla ilgili ilk çalışma ise 1939 yılında Osman Turan tarafından hazırlanmış ve beş tefrika halinde Ülkü dergisinde çıkmıştır (Özkan, 2013. s. 469; Dağıstanlığglu, 2012. s. 1315).

2.1. Destanın Kısa Özeti (Banarlı, 1998. s. 268-269)

Hz. Peygamber Miraç esnasında, diğer bütün peygamberleri de görür. Aralarından birini tanıyamaz ve Cebrail'e o zatın kim olduğunu sorar. Cebrail "-Bu zat Peygamber değildir, der. Bu zat, sizin ruhunuzu Ulu Tanrıya emanet ettiğiniz günden üç yüzyıl sonra yeryüzüne inecek ve sizin dininizi Türkistan da yayacaktır" cevabını verir.

Cebrail'in bu cevabı üzerine Hz. Muhammed çok sevinir, Miraç'tan sonra, gece gündüz bu mübarek ruh için dua etmeğe başlar. Hz Peygamber Satuk Buğra Han' dan sahabelerine de bahseder ve sahabeler de onun ruhunu görmek isteyince peygamber dua eder ve birden karşılarında kırk silahlı atlı belirir. Bu kırk atlı Satuk Buğra Han ve onun kırk yiğidinin ruhlarıdır.

Yıllar sonra, Kaşgar Hükümdarının bir oğlu dünyaya gelir. Adını Buğra Han koyarlar. Buğra Han'ın doğumunda bazı alametler gerçekleşir. Örneğin depremler olur, su kaynakları kurur. Kış olmasına karşın ortalık yeşerir. Falc1 ve kâhinler ilerde Buğra Han'ın Müslüman olacağını bildirirler. $\mathrm{Bu}$ nedenle de öldürülmek istenir. Fakat annesi şayet bir gün gelir falcıların dediği çıkar ve Buğra Han büyüdüğü zaman Müslüman olursa, onun o gün öldürülmesini isteyerek onu kurtarır.

Satuk Buğra Han, on iki yaşındayken kırk arkadaşı ile birlikte ava çıkar. Bir tavşanı kovalar ve tavşan ilerde Hızır'a dönüşür. Satuk Buğra 
Hızır'ın nasihatlerini dinler. Bu olaydan kısa süre sonra Buğra Han'ın babası ölür ve annesi amcasıly evlenir. Satuk Buğra Han amcasını İslâm dinine davet eder. Ancak amcası kabul etmez ve aralarında mücadele olur. Satuk Buğra Han dua eder ve yer yarılarak amcası ortadan kaybolur. Böylece tahta da geçmiş olur.

Hükümdar olunca Türk Ülkesinde İslâmiyet'i yaymağa başlar. Devletin sınırları Amuderya kıyılarından güneyde Kış Kezek taraflarına ve kuzeyde Karakurum'a kadar genişler. Hatta Çin'e kadar uzanır. Daha sonra Buğra Han hastalanır ve Kaşgara dönüp burada ölür. Buğra Han'ın dört kızından biri olan Alanur gördüğü bir aslandan korkar ve bayılır. Ancak uyandığında hamile olduğunu görür. Doğan çocuğa Ali adını verirler.

\section{OTTO RANK'IN KAHRAMANI VE SATUK BUĞRA HAN}

\subsection{Kahraman, sıra dışı bir ailenin çocuğudur.}

Destanda kahramanın annesi ile ilgili ilk bilgiler verilmez ancak rivayetlerde falcıların ilerde Müslüman olacağını haber vermeleri üzerine Satuk Buğra Han öldürülmek istenir ancak annesi tarafindan kurtarılır ve yine babası öldüğünde koruma amaçlı aynı zamanda töre gereği annesi Satuk Buğra Han'ın amcası ile evlenir.

\subsection{Kahramanın Babası bir kraldır.}

Kahramanların genelde babaları kral, yönetici veya soylu kişilerdir. Cevaplanmas1 gereken soru neden kahramanların böyle bir aileden seçilmeleridir. Zira yukarıda da belirtildiği gibi mitlerle başlayan anlatılar destana veya hikâyelere dönüşseler bile hala mitlerin gölgeleri altında kalırlar. Mitin kahramanı ya Tanrı ya da tanrısal özellikleri olan varlıklardır ve bu varlıklar kendi bireyselliklerinden çok kolektife aittirler. Bütün toplumu ilgilendiren kişilerdir. Özellikle destanlar ferdin değil kolektifin anlatıları oldukları için dikkatin toplanacağı kişi de bütün toplumu ilgilendiren birisi olmak zorundadır. Onun alacağı kararlar veya başarıları bütün devleti/toplumu ilgilendirir. Bu nedenle kahramanlar kralın, idarecini veya soylu kimselerin çocukları olarak dünyaya gelirler. Satuk Buğra Han destanında da kahraman hem destanda hem de tarihi kayıtlarda geçtiği üzere Kaşgar Hükümdarının [Karahanlı Hükümdarı Bezir Arslan Han'ın] oğlu olarak dünyaya gelir.

\subsection{Kahramanın ana rahmine düşüş şartları zordur.}

Satuk Buğra Han destanında kahraman anne rahmine düşüş şartları anlatılmaz ancak onun dünyaya geleceği Hz. Peygamber tarafından üç yüz 
yıl öncesinden haber verilir. Hatta Satuk Buğra Han ve arkadaşlarının ruhları sahabelerin istekleri ve Peygamberin duası üzerine üç yıl önceden görünürler.

\subsection{Kahramanın doğumuna karşı kehanetler ve uyarılar vardır.}

$\mathrm{Bu}$ madde Satuk Buğra han için geçerlidir. $\mathrm{O}$ daha dünyaya gelmeden önce ilk kez Hz. Peygamber tarafindan üç asır öncesinden haber verilir. Zira Peygamber miraca yükseldiğinde diğer peygamberleri de görür ancak aralarında bulunan birisini tanıyamaz ve Cebrail'e sorar o da bu kişinin üç asır sonra dini Türkistan'da yayacak olan Satuk Buğra Han olduğunu söyler. Peygamber miraçtan sonra sürekli bu ruh için dua edince sahabeler merak edip sorar ve peygamberin duasiyla kırk atlı sahabelere görünürler.

Üç asır sonra Satuk Buğra han dünyaya geldiğinde falcılar ve kâhinler onun ilerde Müslüman olacağını haber verirler.

\subsection{Kahraman, suya bir kutu içinde bırakılır.}

Satuk Buğra Han Destanında böyle bir motife denk gelinmez.

\subsection{Kahraman, hayvanlar veya iyi insanlar tarafindan korunur.}

Satuk Buğra için geçerli maddelerden birisidir. Doğumundaki kimi işaretlerden sonra kahinler ve falcılar onun gelecekte Müslüman olacağını bildirince onun öldürülmesi istenir ancak annesi falcıların yalan söylediklerini iddia eder ve eğer ilerde Müslüman olursa o zaman öldürülebileceğini söyleyerek onu korur.

3.7. Kahramanı, dişi bir hayvan veya mütevazi bir kadın emzirir.

$\mathrm{Bu}$ madde Satuk Buğra Han için geçerli değildir. Bir başkası tarafindan emzirilme veya bir hayvan tarafindan büyütülme söz konusu değildir. Ancak on iki yaşına gelince ava çıkar ve burada bir tavşanla karşılaşır. Tavşanı epey kovaladıktan sonra tavşan Hızır'a dönüşür ve Satuk Buğra Han Hızır'da epeyce nasihat dinler. Tavşan bilindiği üzere anlatılarda sıklıkla kullanılan bir hayvandır. Mitolojik anlamda üreme, kadınlık, doğurganlık ve bereket anlamalarını çağrıştırır. Ayrıca başı, kulakları, burnu, ayakları nedeniyle kedi, eşek, fare ve köpek gibi hayvanların hulasası gibi düşünülür. Tavşanı önemli kılan bir diğer özelliği de hem yer altında hem yer üstünde yaşamasıdır ki bu durum onun hem yer hem yeraltı bilgisine sahip bir varlık olarak yorumlanmasına yol açar. Özellikle don değiştirme de sıklıkla kullanılır ki bu destan da Hızır önce tavşan donunda Satuk Buğra 
Han'a görünür. Her ne kadar bir emzirme veya büyütme söz konusu değilse de Hızır'dan aldığ 1 öğütler Satuk Buğra Han'1 yeniden kurduğu için bu madde ile az da olsa ilişkilendirilebilir.

\subsection{Kahraman büyür.}

Satuk Buğra Han Hızır'dan aldığı nasihatlerden sonra kendisini yetiştirmekle görevli Ebu Nâsır Sâmâni tarafından yetiştirilir.

\subsection{Ve gerçek ailesini bulur.}

Bu madde de Satuk Buğra Han için geçerli değildir. Zira başka bir aile tarafindan büyütülme veya gizli bir yere gönderilme söz konusu değildir.

\subsection{Babasından intikamını alır.}

Satuk Buğra Han küçük yaşlarda öz babasını kaybeder annesi de geleneğe uyarak amcası ile evlenir. Dolayısıyla amcası Buğra Han'ın üvey babası olur. Aralarında din değiştirme yüzünden ihtilaf çıkar ve amcasıyla üvey babasıyla- yaptığı mücadelenin sonunda dua ettiğinde yer yarılır ve amcası kaybolur. Bu nedenle bu maddenin de az çok uyuştuğu söylenebilir.

3.11. Kahraman, halk tarafindan tanınır ve kabul edilir / 12. Kahraman rütbe kazanır, yükselir ve onurlanır.

Amcasından sonra tahta çıkar ve uzun yılar hükmeder. Onun döneminde İslam coğrafyası Amuderya boylarına, Kız Kezek'e, Karakurum'a ve Turfan'a kadar genişler. İktidarıyla ilgili bir sorun olmadan epeyce süre ülkesinin idare eder. Tahtıyla ilgili mücadele yoktur ancak coğrafyasını genişletmek adına sürekli savaş halindedir. $\mathrm{Bu}$ süreç düşünüldüğünde Rank'ın bu maddesi de Satuk Buğra Han için geçerli say1lır.

\section{SONUÇ}

Destanlar aynı zamanda bir tür geçiş türüdür. Zira bir taraftan mit dünyasından yavaş yavaş kopmalar başlarken diğer taraftan da halk hikâyelerine doğru bir yönelim olmuştur. Destanlar işte bu geçişi sağlayan eserlerdir. Diğer taraftan destanları sadece bir türsel geçiş değil aynı zamanda bütün kolektifi derinden etkileyen önemli olayların da geçiş eserleri olarak yorumlamak gerekir. Zira coğrafya değişikliği, yeni devlet kuruluşu, din değişikliği, dil değişikliği veya yeni tanınan kültürlerle iletişim her açıdan destan metinlere konu edilmiştir. Satuk Buğra Han destanı tam da bu en önemli değişikliklerin gerçekleştiği bir dönemin anlatısıdır. Bir toplum yeni bir dinle karşılaşmakta hatta eski inancını terk ederek yeni bir din seçmektedir. $\mathrm{Bu}$ durum haliyle kolektif açısından oldukça önemli bir 
aşamadır. Otto Rank'ın "Kahraman, halk tarafından tanınır ve kabul edilir" ve "Kahraman rütbe kazanır, yükselir ve onurlanır" gibi maddelerini Satuk Buğra için daha etkili kılan da büyük ihtimalle istenen bu köklü değişiklik ile halkını hem tanıştıran hem de onları bu dine daha rahat taşıyacak kişi oluşundan kaynaklanmaktadır.

Batı kaynaklı anlatılardan hareketle geliştirilen bu kalıpların Türk anlatılarına tatbikinde kimi maddelerin Türk anlatıları için geçerli olmadığı görülür. Zira toplumların hayat kabulleri, eşya veya varlığ kabulleniş biçimlerinden aile içi hiyerarşileri, gelenekleri, kahramandan beklentileri gibi özellikleri birbirinden farklıdır. Sizin için son derece ehemmiyet verilmesi gereken bir şey başak bir toplum için nasıl sıradan ise başka toplumlar için kutsal olan da sizin için değersiz gelebilir. $\mathrm{Bu}$ nedenle özellikle kolektif belleklerin yaratması olan edebi ürünler değerlendirilirken batı kaynaklı kalıplar çoğu zaman havada kalabilmektedir. Daha önceden yukarıda zikredilen çalışmalarda da -Lord Raglan'ın kalıbının uygulamalarıbenzer durumlar ortaya çıkmıştır. Bu nedenle özel olarak Türk halk anlatıları için benzer kalıpların hazırlanması bir ihtiyaçtır.

Otto Rank'ın kalıbı ve destan iliş̧kisi aşağıda tablolaştırılmış̧ır:

\begin{tabular}{|c|c|c|}
\hline \multicolumn{2}{|r|}{ Otto Rank'ın Kalıbı } & Satuk Buğra Han Destanı \\
\hline 1 & Kahraman, sıra dışı bir ailenin çocuğudur & Hükümdar ailesinden gelir \\
\hline 2 & Kahramanın, babası bir kraldır & Kaşgar Hükümdarının Oğludur \\
\hline 3 & Kahramanın ana rahmine düşüş şartları zordur & Yok \\
\hline 4 & $\begin{array}{l}\text { Kahramanın doğumuna karşı kehanetler ve uyarılar } \\
\text { vardır }\end{array}$ & $\begin{array}{lll}\begin{array}{l}\text { Depremler, } \\
\text { kuruması }\end{array} & \text { su } & \text { kaynaklarının } \\
\end{array}$ \\
\hline 5 & Kahraman, suya bir kutu içinde bırakılır & Yok \\
\hline 6 & $\begin{array}{l}\text { Kahraman, hayvanlar veya iyi insanlar tarafindan } \\
\text { korunur }\end{array}$ & Annesi korur \\
\hline 7 & $\begin{array}{l}\text { Kahramanı, dişi bir hayvan veya mütevazi bir kadın } \\
\text { emzirir }\end{array}$ & Erginlemesi hocası Nasır ile olur \\
\hline 8 & Kahraman büyür & $\mathrm{Bu}$ süreç anlatılır \\
\hline 9 & Ve gerçek ailesini bulur. & Yok \\
\hline 10 & Babasından intikamını alır. & $\begin{array}{l}\text { İntikam değil ama amcası/üvey } \\
\text { babasını yener }\end{array}$ \\
\hline 11 & Kahraman, halk tarafından tanınır ve kabul edilir & Satuk Buğra Han için geçerlidir \\
\hline 12 & Kahraman rütbe kazanır, yükselir ve onurlanır & Satuk Buğra Han için geçerlidir \\
\hline
\end{tabular}

$\mathrm{Bu}$ tabloya göre on iki maddeden 3,5,7 ve 9. maddeler hariç diğer maddeler Satuk Buğra Han ile ilişkilendirilebilir.

\section{KAYNAKLAR}

Aktaş, E. (2014). Lord Raglan'ın kahraman kalıbı ve Alp Han Orba. Siberian Studies, 2/4, 13-30. 
Banarlı, N. S. (1998). Resimli Türk edebiyatı tarihi, Cilt I, İstanbul: MEB Yayınları. BARS, M. E. (2014). Lord Raglan'ın geleneksel kahraman kalıbı ve Kartıga Pergen Destan1, IJLET, 2, 120-134.

Çobanoğlu, Ö. (2011). Türk dünyası epik destan geleneği. Ankara: Akçağ Yayınları.

Çobanoğlu, Ö. (2012). Halkbilim kuramlarl ve araştırma yöntemlerine giriş, Ankara: Akçă̆ Yayınları.

Dağıstanlığlu, B. E. (2012). Tezkire-i Buğra Han’ın Çağatayca Yazılmış Bir Nüshası (metin- dil incelemesi- tıpkıbasım). Turkish Studies, 7/4, 13131393.

Düzgün, Ü. K. (2007). Başkurt destanlarının tipolojisi. Yayımlanmamış Doktora Tezi, Gazi Üniversitesi, Ankara.

Hunkan, Ö. S. (2009). Satuk Buğra Han. İslam Ansiklopedisi, cilt 36, 181-182, İstanbul: Türkiye Diyanet Vakfı Yayınları.

Köse, N. (1999a). Lord Raglan'ın geleneksel kahraman kalıbı ve "Kococaş". Milli Folklor, 43, 19-23.

Köse, N. (1999b). Lord Raglan'ın geleneksel kahraman kalıbı ile Kurmanbek ve Kurbanbek. Gazi Üniversitesi Gazi Eğitim Fakültesi Dergisi, Dr. Himmet Biray Özel Sayıs1, Ankara, 253-261.

Köse, N. (2000). Raglan'ın geleneksel kahraman kalıbı ve Türk halk hikâyeleri. Milli Folklor, 45, 22-39.

Oğuz, M. Ö. (1998). Lord Raglan'ın geleneksel kahraman kalıbı ve Boğaç Han. Milli Folklor, 5 (40), 2-6

Oğuz, M. Ö. (1999). Lord Raglan'ın geleneksel kahraman kalıbı ve Basat. Milli Folklor, 5 (41), 2-8.

Özkan, İ. (2013). Abdülkerim Satuk Buğra Han destanı, Bengü Bitig Dursun Yıldırım Armağanı. (Ed. Bülent Gül, Ferruh Ağca, Faruk Gökçe) Türkbilig Türkoloji Araştırmaları Yayın Dizisi 01, Ankara: Türkbilig-Öncü Kitapss. 467-488.

Raglan, L. (1998). Geleneksel kahraman. (Çev. Metin Ekici). Milli Folklor, 5 (37), 126-138.

Zariç, M. (2012). Axel Olrik'in epik yasaları ve Lord Raglan'ın kahraman kalıbı açısından Ağrıdağı Efsanesi romanı. Turkish Studies, 7/4, 3337-3349. 